\title{
Evaluation of the Deposition of Nanoparticles on the Human Respiratory Tract from the Burning of Diesel/ Biodiesel/ Additive
}

\author{
Clara Rodrigues Pereira ${ }^{1 *}$, Pedro Bancillon Ventin Muniz ${ }^{2}$, Katheelin Rios Santa Rosa ${ }^{2}$, \\ Lílian Lefol Nani Guarieiro ${ }^{2}$, Ednildo Andrade Torres ${ }^{3}$ \\ ${ }^{1}$ Integrated Campus of Manufacturing and Technology, Senai Cimatec University Center, Master's Degree Course on \\ Sustainable Development; ${ }^{2}$ Senai Cimatec University Center; ${ }^{3}$ Federal University of Bahia;
}

This study aimed to evaluate the deposition in the respiratory tract of nanoparticles $(11.5 \mathrm{~nm}$ to $365.2 \mathrm{~nm})$ from the burning of diesel, biodiesel, and additives. The studied fuels were pure diesel (D), a binary mixture of pure diesel with $11 \%$ biodiesel (B11), and a ternary mixture of pure diesel, with $11 \%$ biodiesel and with the biocatalyst Xmile (B11X). The impact of nanoparticles on health was assessed using the MPPD lung model. From the tests, the burning of the studied fuels showed a concentration of some particles in the accumulation mode (50nm to $120 \mathrm{~nm}$ ). When comparing fuels, it was clear that B11 emits more particles and has a greater deposition capacity in the lung. B11X is efficient in reducing pollutant emissions as well as impacting human health.

Keywords: Deposition. Respiratory Tract. Biodiesel. MPPD.

Abbreviations: MPPD: Multiple-Path Particle Dosimetry Model.

\section{Introduction}

Diesel engines play an important role in the world economic scenario, due to higher energy productivity, higher power, and considerable durability [1]. These particularities are associated with many applications such as transportation, pumps, and electricity generators. Despite having such applicability, diesel engines are responsible for the growth of pollutants in the atmosphere, such as total hydrocarbons, nitrogen oxides, carbon monoxide, and particulate matter (PM) [2].

Atmospheric particles material (PM) consists of heterogeneous mixtures of solid and liquid particles suspended in the air that vary in size and chemical composition, such as nitrates; sulfates; elemental and organic carbon; organic compounds (for instance, polycyclic aromatic hydrocarbons); biological compounds (for example, endotoxin,

Received on 10 October 2020; revised 22 December 2020. Address for correspondence: Clara Rodrigues Pereira. Rua Embira/ No154/Condomínio Etco/ Apartamento 1903C. Phone: (71) 98172-5426. E-mail: clara.r.pereira@gmail. com. Article selected from VI International Symposium on Innovation and Technology (SIINTEC).

J Bioeng. Tech. Appl. Health

(C) 2021 by SENAI CIMATEC. All rights reserved. cell fragments, viruses); and metals (for example, iron, copper, nickel, zinc, and vanadium) [3,4].

The PM can be classified according to its transport capacity in the air, which is associated with particle diameter sizes. Its classification is Coarse (PM10), Fine (PM2.5), and ultrafine (PM0.1) [5]. PM10 has an aerodynamic diameter smaller than 10 micrometers $(\mu \mathrm{m})$; PM2.5 has an aerodynamic diameter smaller than $2.5 \mu \mathrm{m}$ and PM0.1 has an aerodynamic diameter less than $0.1 \mu \mathrm{m}$ [5]. The particulate matter emitted by diesel engines consists of a predominance of fine particles (PM2.5) and ultrafine particles (PM0.1) [6].

Improving engine performance and regulate the emission of pollutants, additives, also called oxygenated fuels, are added to diesel [7]. Oxygenated additives mixed with diesel fuels promote combustion and octane processes without emitting a high amount of pollutants to the atmosphere [8]. Generally, the most applied additives are alcohols (butanol, propanol, methanol, and ethanol), ethers (diethyl ether, tert-butyl methyl ether), and esters (acetoacetic esters, dicarboxylic acid esters, and methyl esters) [8]. The application of these additives in diesel inhibits the formation of particles considering the existence of less unsaturated micro molecules, such as $\mathrm{C}_{2} \mathrm{H}_{2}$, that contribute to the reduction of PM emissions in the combustion process [9]. 
The particulate matter from diesel engines is not only responsible for a huge impact on the atmosphere but can result in cardiovascular, respiratory, and carcinogenic diseases, considering that inhalation can be a means of contact between the human organism and the PM [7]. This interaction happens in a way that the smaller the particle, the higher the capacity to absorb organic and inorganic compounds in the respiratory tract [3]. Fine particles (PM2.5), for example, when inhaled run through the bronchioles and alveolus (where gas exchange occurs) inducing carcinogenic (lung cancer symptoms) and mutagenic (breaks and changes in the genetic chain) effects [3]. Therefore, the use of additives in diesel cycle engines is not only intended to reduce the emission of atmospheric pollutants, but also to reduce the impact that particulate matter can cause on the human respiratory tract.

The current scenario of COVID-19 is disturbing, especially in countries with a high level of pollution and the incidence of deaths resulted from the emission of PM. These factors can lead to more serious symptoms with the action of the virus which has been decimating. However, when introducing the measures imposed during quarantine, it was possible to visualize a scenario with reduced emissions from transport and industries, enabling an improvement in air quality [10]. An India study from March 2020, in which the objective was measuring the incidence of pollutants in the atmosphere after the measures imposed to contain the spread of COVID-19 [11], demonstrated a significant improvement in air quality in a period when there is no intense car flow in cities due to the measures implemented during the COVID-19 pandemic [10].

The objective of this study was to evaluate the deposition of nanoparticles (11.5nm to $365.2 \mathrm{~nm}$ ) from the burning of diesel, biodiesel, and additives in the respiratory tract.

\section{Material and Methods}

The methods of this study are represented in Figure 1.
The experimental phase of the study used three fuels: pure diesel, B11 (a binary mixture of pure diesel with 11\% biodiesel), and B11X (a ternary mixture of pure diesel, with $11 \%$ biodiesel and with the biocatalyst Xmile). An Agrale diesel engine, model N-790, speed $1700 \mathrm{rpm}$ was used, coupled to a hydraulic dynamometer (Schenck) with a maximum rotation of $10,000 \mathrm{rpm}$. Integrating this system, a partial dilution tunnel was used to sample the particulate matter with a partial exhaust dilution rate of 24.

A Nanoscan SMPS 3910 particle counter was coupled to the exhaust system to measure the concentration and distribution of the particulate material size (11.5nm to $365.2 \mathrm{~nm}$ ) according to the variation of its concentration, in a 10 minutes time range with three replicates for each fuel (D, $\mathrm{B} 11$, and $\mathrm{B} 11 \mathrm{X})$.

We used the MPPD software (Multiple-path Particle Dosimetry Model) (version 3.04) with the experimental data of this study to evaluate how the variation of particle sizes from the vehicle emission behave in the respiratory tract. This software is based on a lung geometry model by Yeh and Schum (1980) that simulates the deposition of particulate material in different regions from the anatomy of the species studied, by adopting a dichotomous branch in the airway structure [11]. It consists of simple and multiple path methods to track the airflow and calculate the aerosol deposition in the lungs.

The single path method calculates deposition in a typical path by airway generation, while the multipath method calculates particle deposition in all airways in the lungs [12]. This model provides the study of regional deposition, extrathoracic, tracheobronchial, and alveolar regions, where morphometric options are available to idealize the lung. Data such as PM properties and exposure conditions must be provided by standards or values specified by the user, in which the deposition fraction can be estimated for particles with a size range between $1 \mathrm{~nm}$ and $100 \mu \mathrm{m}$ [12].

The model chosen in this study was the stochastic model that aims to calculate the 
Figure 1. Flowchart of the methods applied in the study.

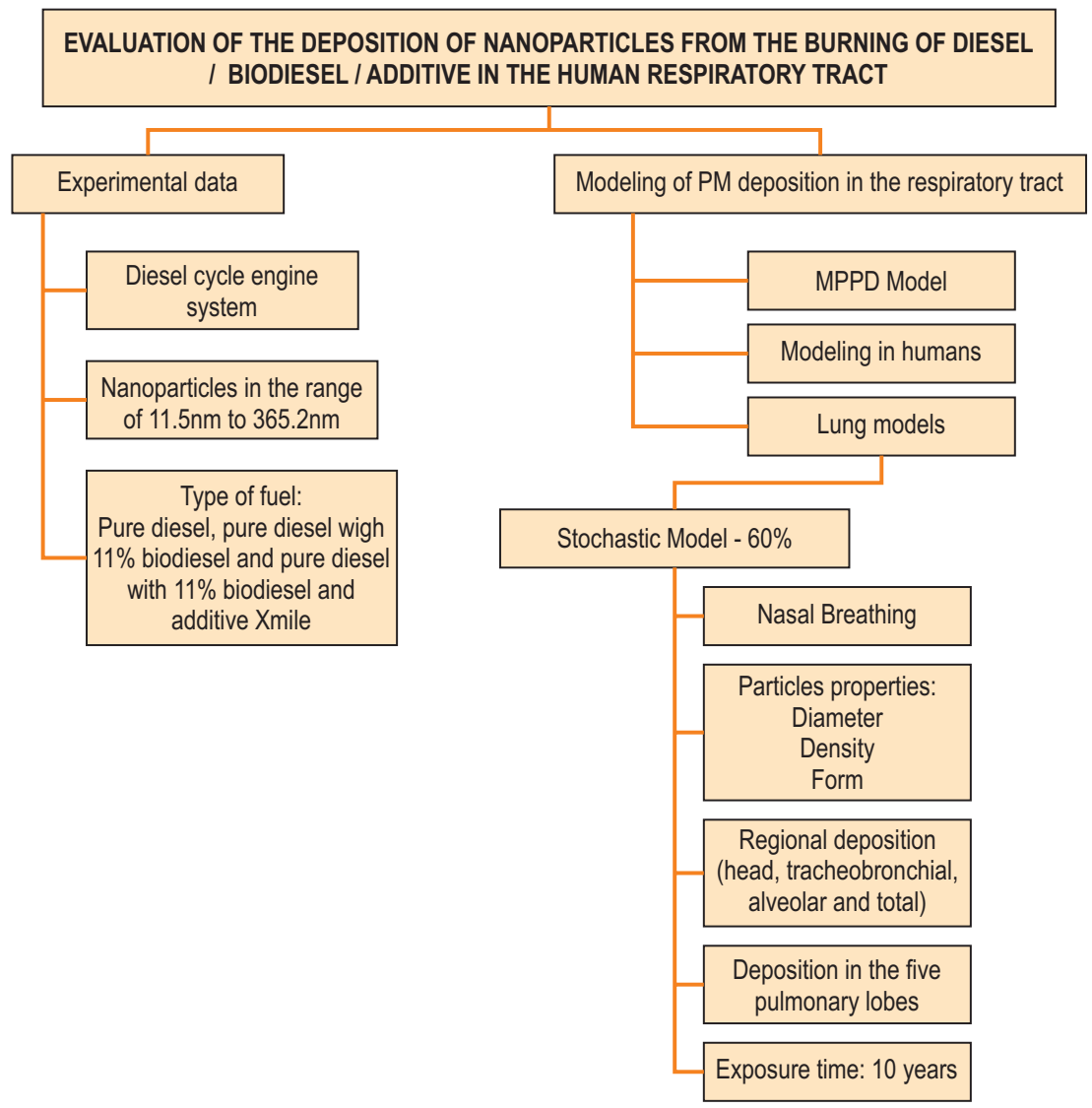

Figure 2. The flow of MPPD modeling.
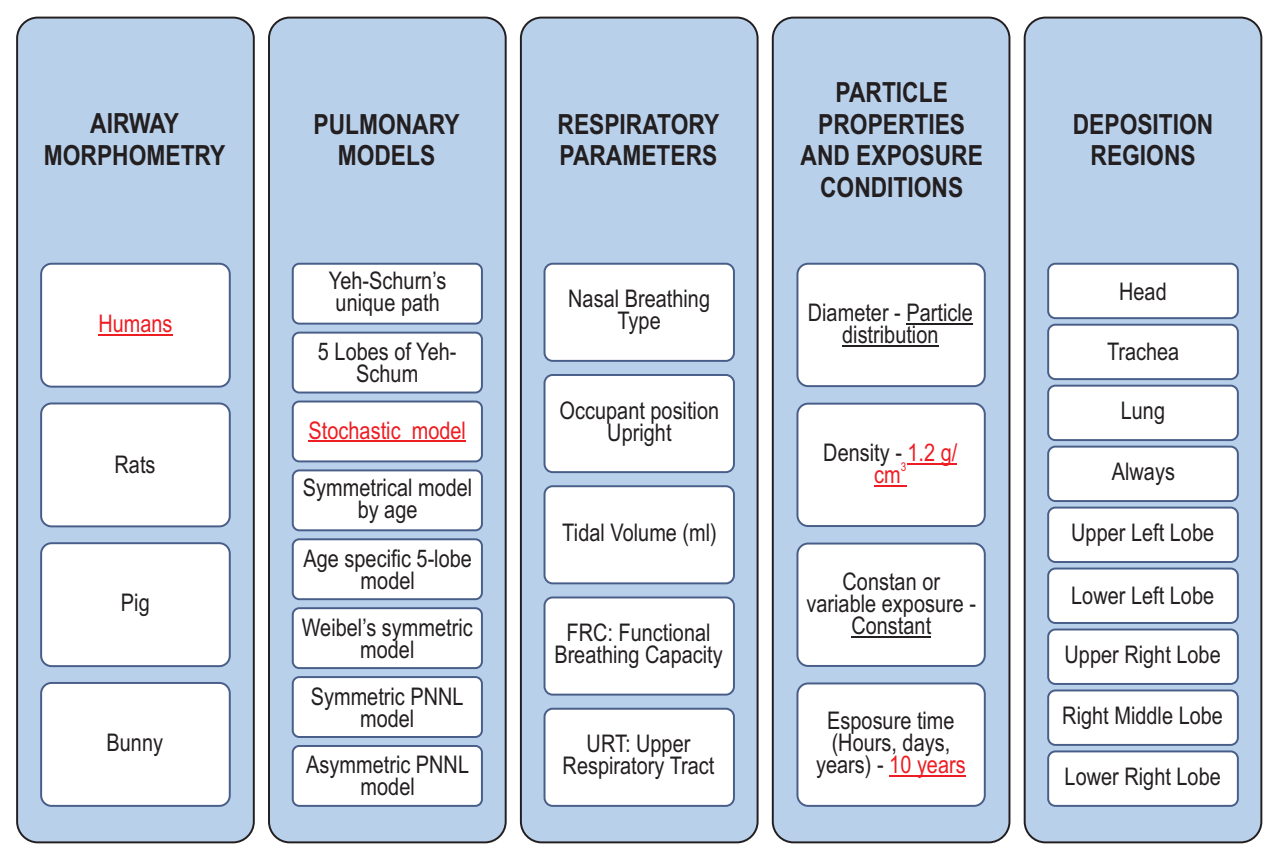

www.jbth.com.br 
deposition of PM in the lung in some locations of the human respiratory tract, such as: regional (head, tracheobronchial, alveolar, and total) and lobular (in the five pulmonary lobes) [12]. This model provides an estimate of the variability of the lung dose received by humans, generating more realistic deposition results. Modeling in MPPD occurs according to the input data steps, essential to measure the level of PM concentration in the lung (Figure 2).

\section{Results and Discussion}

The emissions of particulate material for the three fuels tested presented accumulation mode concentrations (50 $\mathrm{nm}$ to $160 \mathrm{~nm}$ ) (Figure 3).

According to the literature, particles emitted by diesel engines are in the accumulation mode, in the range of $50 \mathrm{~nm}$ to $200 \mathrm{~nm}$ [13]. It means that the results obtained were satisfactory. It is also possible to observe that in a large part of the graph the error bars overlap, emphasizing that the three fuels have a statistically similar size and the number of particles distribution. However, in the size range from $50 \mathrm{~nm}$ to $160 \mathrm{~nm}$, a difference in this distribution was observed. The addition of biodiesel promotes the reduction of the total mass of PM, but when compared to pure diesel it emits more ultrafine particles which are more harmful to health [13].

Therefore, the diameters that are included on the accumulation mode of the graphic obtained $(50 \mathrm{~nm}$ to $160 \mathrm{~nm})$ were used as input data in the MPPD. The main goal of this simulation was to evaluate the impact of PM on the human respiratory tract.

Considering that the B11 fuel had the highest concentrations of PM emission, Figure 4 shows the deposition of PM for the entire lung and for the 5 pulmonary lobes. It shows that the smaller the diameter, the greater is the deposition fraction in the lung. The right lower lobe is the place of the greatest accumulation of particles when compared to the left upper lobe and right middle, in which the deposition of particles is lower.
Figure 5 represents the deposition fraction for the different generations or regions (from 0 to 23) of the human respiratory tract. It also shows that the smaller the diameter, the greater the particle penetration capacity in the different regions of the respiratory tract.

Figure 6 (A-F) shows the variation in the number of particles per alveolus, in the entire lung and each lobe for the three fuels studied. It also presents that the numerical deposition per alveolus was higher for B11, especially for the diameter 64.9, which corresponds to the peak of the PM emission graph for the whole lung and the 5 pulmonary lobes. The behavior of B11X and D also corresponds to the MP emission graph of the diesel cycle engine, in which the deposition of particles by alveolus is greater in B11X than in D for all pulmonary regions. The deposition flow by size is the same, the smaller the diameter the greater the deposition fraction in the respiratory tract.

The simulation considered the following scenario of exposure to pollutants: the individual at the bus stop waiting for 1 hour a day, for 7 days a week, for 10 years. The sizes $64.9 \mathrm{~nm}$ and 86.6 were chosen to show how this type of exposure occurs, considering the B11 fuel (Figure 7).

The exposure to particulate material increases over the years, however, for the two diameters chosen, the level of exposure is almost the same.

This work focused on the evaluation of the deposition of nanoparticles (11.5nm to $365.2 \mathrm{~nm}$ ) for pure diesel, the B11 fuel, and the B11X fuel. We concluded that B11 emits more ultrafine particles in comparison to pure diesel despite the reduction of the total PM mass. The addition of the additive Xmile proved to be efficient because it contributed to reducing particulate emissions, especially the ultrafine ones.

The same result was observed in the analysis of the impact of particulate emissions from these fuels studied on the respiratory tract. As it emits more small particles, the B11 fuel was the one with the greatest capacity for depositing particles in the pulmonary regions, which proves that the smaller 
Figure 3. Distribution of the number and size of fuel particles D, B11, and B11X.

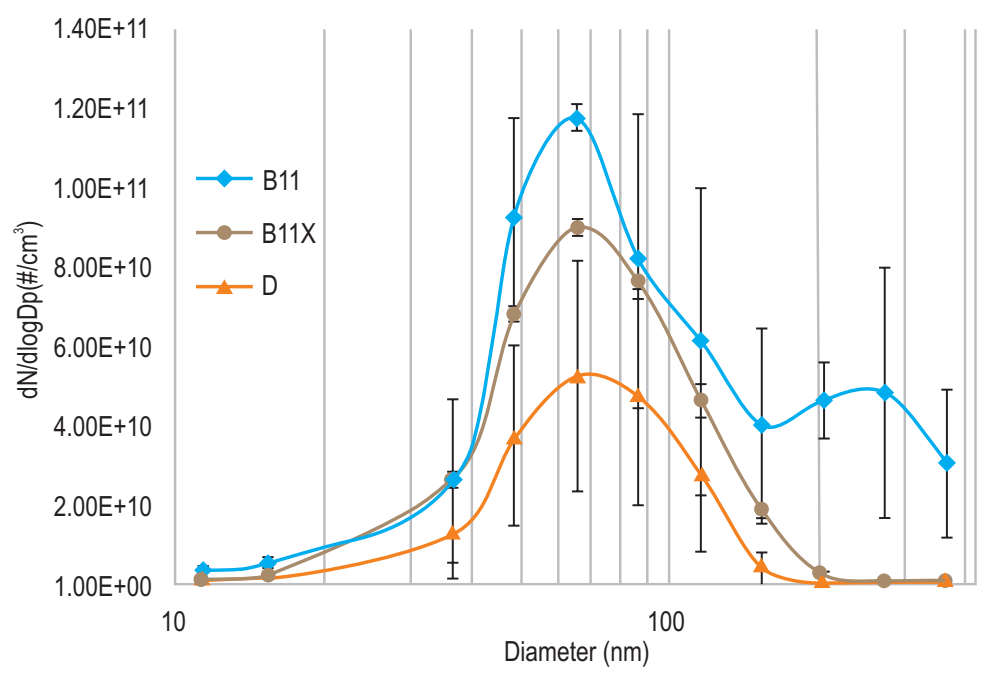

Figure 4. Fractional deposition of MP in the airways in the lung lobes for the B11 fuel.

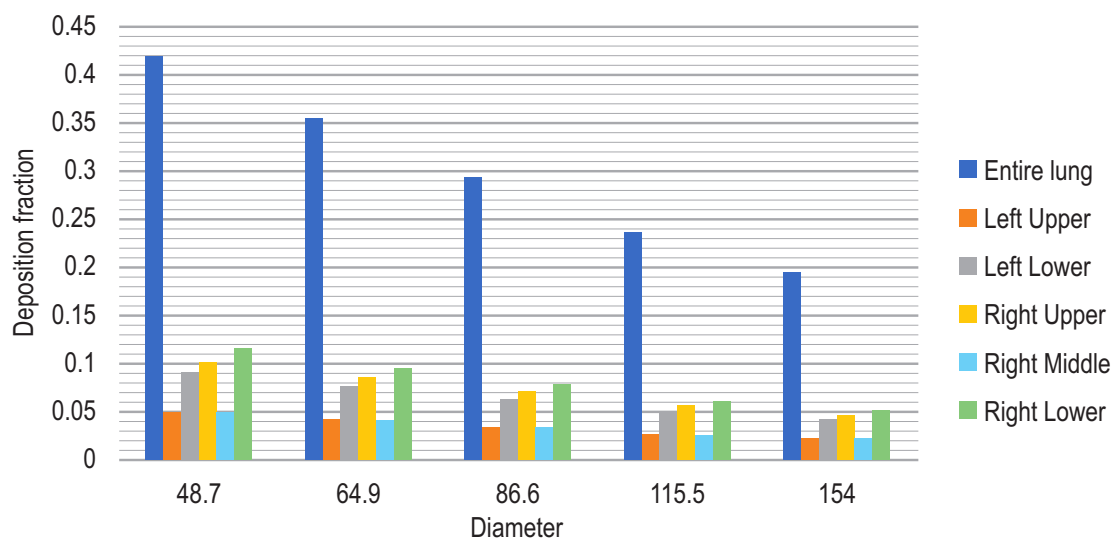

Figure 5. Fractional deposition of B11 fuel particles by generation number for each aerodynamic particle diameter.

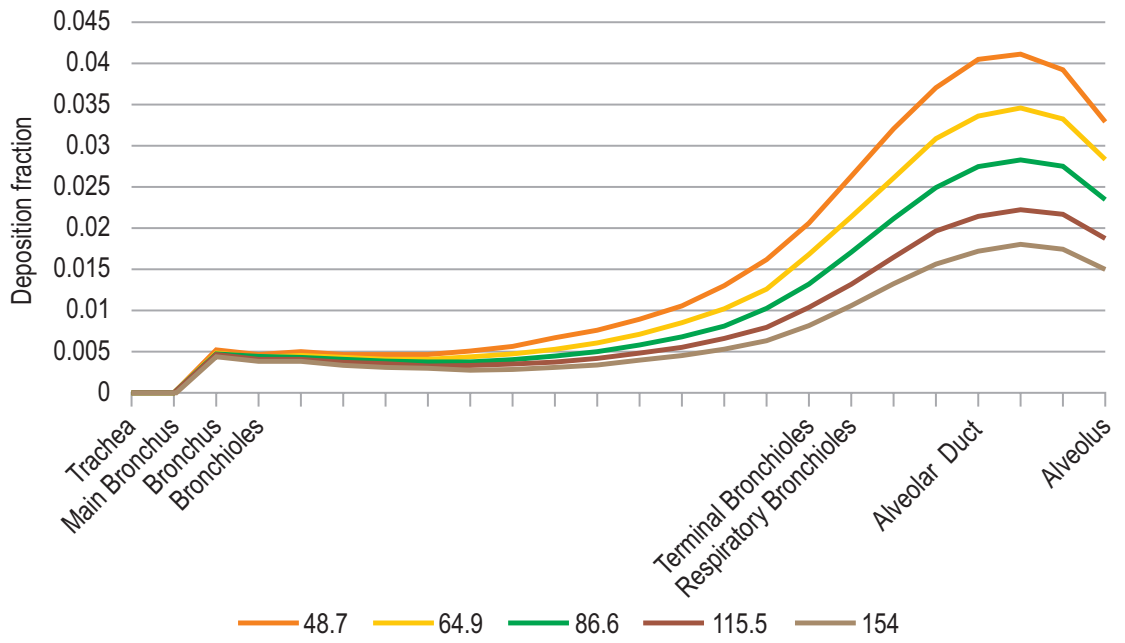


Figure 6. Deposition fraction of the number of particles per well for the B11, B11X and D. A. Entire Lung. B. Left upper. C. Left lower. D. Right upper. E. Right middle. F. Right lower.
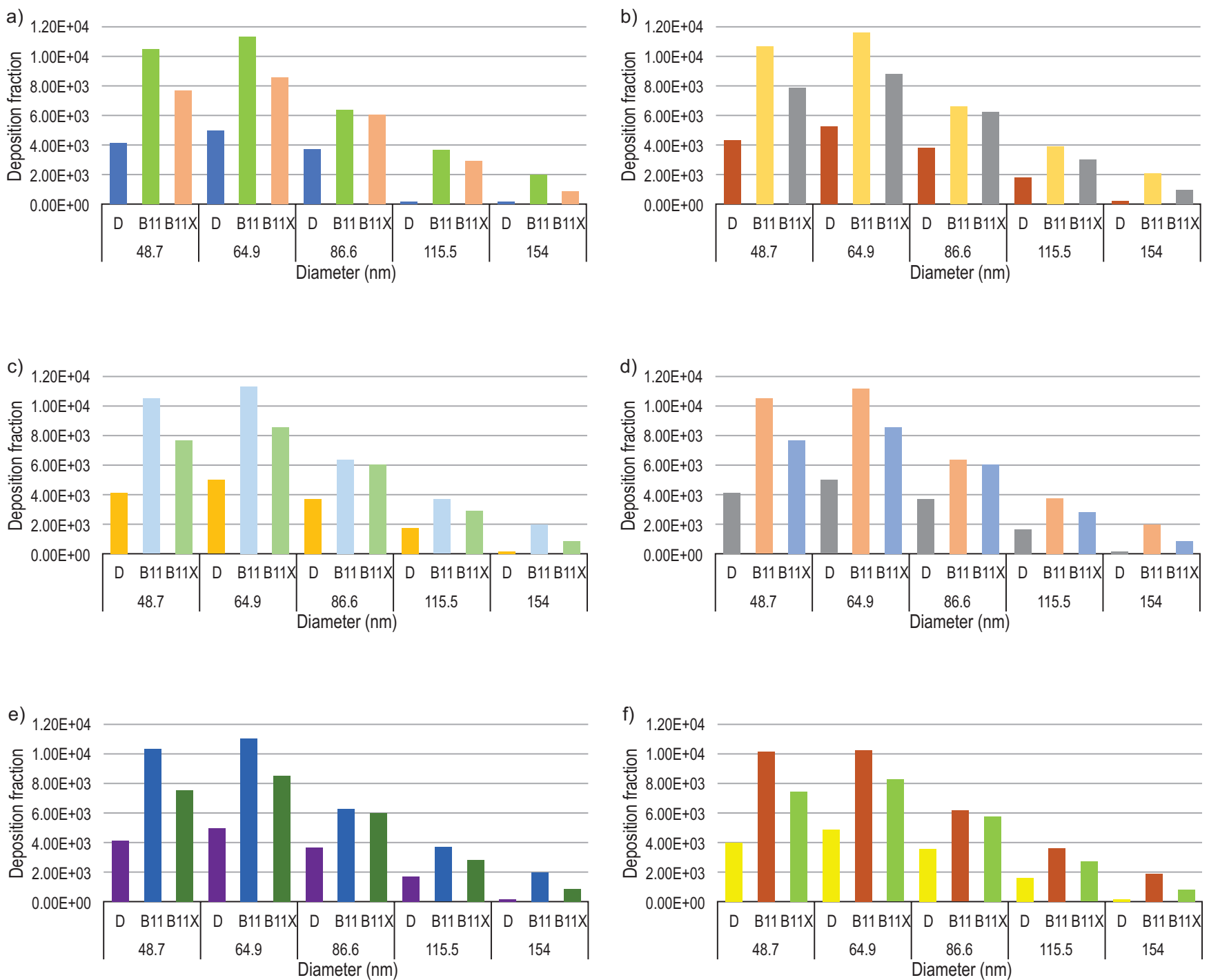

Figure 7. Alveolar deposition over 10 years for particles with $64.9 \mathrm{~nm}$ and $86.6 \mathrm{~nm}$ in diameter for the B11 fuel.

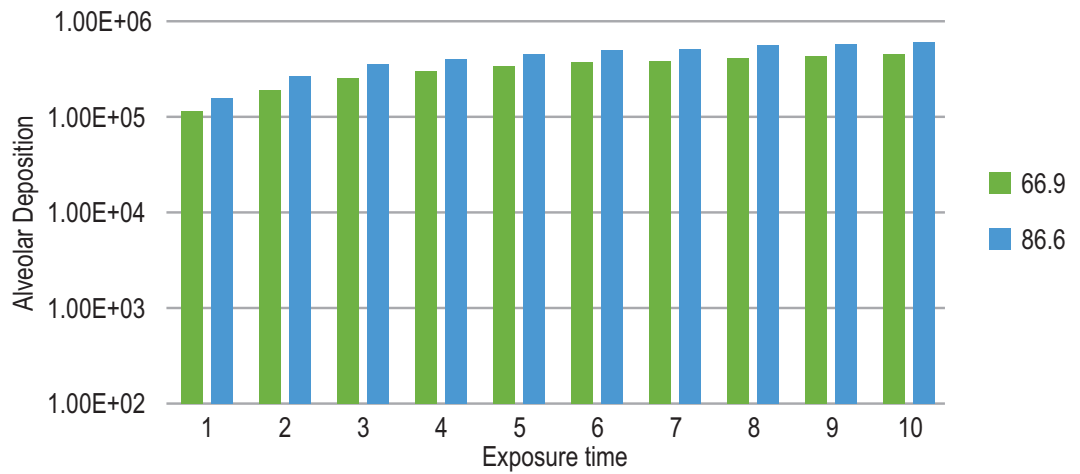

www.jbth.com.br 
they are, the bigger the chance of penetrating the lungs, especially the alveolus. On the other hand, the addition of Xmile additive promotes the reduction of particle emissions and contributes to less impact on the human respiratory system.

\section{References}

1. Khan M et al. Role of oxygenated additives for diesel fuel blend "a short review". Journal of Applied Sciences 2015;15(4):619-625.

2. Fayad MA, Tsolakis A, Martos FJ. Influence of alternative fuels on combustion and characteristics of particulate matter morphology in a compression ignition diesel engine. Renewable Energy 2020;149:962-969.

3. Kim K-H, Kabir E, Kabir S. A review on the human health impact of airborne particulate matter. Environment International 2015;74:136-143.

4. Ali MU et al. A systematic review on global pollution status of particulate matter-associated potential toxic elements and health perspectives in urban environment. Environmental Geochemistry and Health 2018:1-32.

5. Scafi FT et al. Modeling of particle size distribution at the exhaust of internal combustion engines. In: Nonlinear Systems and Circuits in Internal Combustion Engines. Springer, Cham, 2018:33-46.

6. Colasanti $\mathrm{T}$ et al. Diesel exhaust particles induce autophagy and citrullination in Normal Human Bronchial Epithelial cells. Cell death \& Disease 2018;9(11):1-15.

7. Guarieiro LL, Guarieiro ALN. Vehicle emissions: What will change with use of biofuel? In: Biofuels Economy, Environment and Sustainability 2013;[s.l.].

8. Kumar MV, Babu AV, Kumar PR. The impacts on combustion, performance and emissions of biodiesel by using additives in direct injection diesel engine. Alexandria Engineering Journal 2018;57(1):509-516.

9. Geng $\mathrm{P}$ et al. Effects of alternative fuels on the combustion characteristics and emission products from diesel engines: A review. Renewable and Sustainable Energy Reviews 2017;71:523-534.

10. Sharma $\mathrm{S}$ et al. Effect of restricted emissions during COVID-19 on air quality in India. Science of the Total Environment 2020;728:138878.

11. Asgharian B et al. Computational modeling of nanoscale and microscale particle deposition, retention and dosimetry in the mouse respiratory tract. Inhalation Toxicology 2014;26(14):829-842.

12. Manojkumar N, Srimuruganandam B, Nagendra SMS. Application of multiple-path particle dosimetry model for quantifying age specified deposition of particulate matter in human airway. Ecotoxicology and Environmental Safety 2019;168:241-248.

13. Guarieiro LLN et al. Assessment of the use of oxygenated fuels on emissions and performance of a diesel engine. Microchemical Journal 2014;117:94-99. 